\title{
Apresentação do Dossiê "Cosmopolitismos"
}

Boa parte dos artigos que constituem este dossiê "Cosmopolitismos", que a revista Novos Olhares generosamente acolhe neste número especial, foi apresentada no contexto do Grupo de Trabalho Cultura das Mídias, no 23‥ Encontro da Compós, realizado em maio de 2014 na UFPA. O conjunto destes trabalhos representa a consolidação de um grupo que já conta com mais de dez anos de atuação no campo de pesquisa em Comunicação. Neste sentido, esta publicação é também a confirmação da importância de um eixo de discussão interessado em problematizar o papel exercido pelos meios de comunicação nos embates e tensões decorrentes das disputas por representação cultural, simbólica e identitária. Os trabalhos aqui apresentados, portanto, evidenciam o campo das mídias como um espaço de negociações, deslocamentos e reconfigurações, no qual se encontram os processos de produção de sentido.

Ao abordar a Cultura das Mídias, o recorte efetuado pela proposta do GT Ihe imprime uma singularidade no ambiente midiático, e sua produção de conhecimento vem se confirmando com as pesquisas apresentadas nos sucessivos Encontros, as quais indicam novos aportes teóricos a partir de objetos de investigação diversos, refletindo dinâmicas ocorridas nas práticas discursivas, nas formulações narrativas e na esfera tecnológica da comunicação, aspectos relevantes da expansão da cultura midiática.

Ao longo dos seus doze anos de existência, o GT Cultura das Mídias afirmou-se como um espaço produtivo de interlocução entre pesquisadores de diferentes regiões do país, interessados em pensar a cultura contemporânea em seus aspectos sociopolíticos e estéticos, tendo como foco a produção midiática em relação aos meios e mediações. O conjunto dos textos aqui reunidos atesta esta diversidade regional na origem institucional de seus autores, assim como a pluralidade de temas e abordagens que confirmam a interdisciplinaridade e multiplicidade de perspectivas que sempre orientaram as discussões do grupo. Pode-se dizer que esta diversidade expressa a própria trajetória do GT Cultura das Mídias, que se caracteriza pela continuidade em diferença, com um processo de complexificação das abordagens e das metodologias, assim como da constituição de novos objetos, face à ampliação do campo da Comunicação e ao crescente afluxo de experiências mediadas na vida diária.

Um exemplo é este dossiê, no qual elencamos discussões em torno da noção de cosmopolitismos. $\mathrm{O}$ assunto veio à tona, como dissemos, no referido Encontro da Compós, mas sem que houvesse uma combinação prévia a respeito. De fato, naquela ocasião, à medida que os participantes traziam resultados de suas pesquisas e apresentavam textos que eram lidos e discutidos por todos os demais integrantes do GT, tornou-se evidente uma certa convergência temática acerca de questões relacionadas a cidades ou urbanidades, de hoje e de tempos 
passados, com aspectos tensionados a partir de perspectivas locais e também globais, frequentemente refletidas no âmbito das culturas das mídias, como os próprios artigos confirmavam.

Um texto parecia inclusive constituir uma espécie de guia no rumo das problemáticas convergentes: "Cosmopolitismo(s) em Tempos Midiáticos: um Desafio Contemporâneo", de Renato Cordeiro Gomes. Nele, o autor trazia uma reflexão acerca do próprio conceito "cosmopolitismo(s)", relacionado a diversas concepções filosóficas e históricas, com um olhar especialmente voltado a interpretações do Brasil ao longo de sua história republicana. Na sua argumentação, Gomes adensa o debate em torno do conceito cosmopolitismo através de seus registros contemporâneos, ligados ao multiculturalismo, à globalização e às novas tecnologias de comunicação, a partir dos quais percebe uma espécie de "aclimatação aos espaços e às temporalidades várias e simultâneas". A modernidade pretendida do início do século XX dialogava com os precisos limites do nacional, ainda que reconfigurados pelas relações problemáticas entre o próprio e o alheio, conforme prognosticavam nossos intelectuais mais vanguardistas, em que merece destaque no texto a crônica de João do Rio, "o escritor da Belle Époque mais afinado com o cosmopolitismo". Renato Cordeiro Gomes atualiza a presença, na virada do século XXI, das tensões de nossa modernidade pautadas pela dialética entre cosmopolitismo e provincianismo, e seus desdobramentos global e local, centro e periferia, autonomia e dependência, e ainda universalismo e nacionalismo. Nessa perspectiva contemporânea trazida pelo autor, o cosmopolitismo se pluraliza, diagnosticando as suspeitas dos tradicionais limites da Nação a partir de processos globalizados, que fazem deslocar a discussão para as margens nas quais Silviano Santiago identifica o "cosmopolitismo do pobre". É nesse movimento, operando na atualização formulada pelas margens, que Renato Cordeiro Gomes tensiona ainda mais o conceito, ao arrolar indagações a partir da provocação de Santiago, as quais evidenciam a permanência da dialética tão cara a nossa formação cultural.

É também nessa chave de atualização da discussão sobre cosmopolitismos, no plural, que Vera Lúcia Follain de Figueiredo, vai refletir sobre as fronteiras que complexificam a organização dos fluxos migratórios contemporâneos no artigo "Movimentos Migratórios e Cidadania: a Onipresença das Fronteiras". Restituindo ao termo cosmopolitismo(s) a potência que parecia ter sido eclipsada em função da ubiquidade do conceito de globalização nas reflexões sobre a sociedade contemporânea, a autora remonta às armadilhas construídas em torno das dicotomias modernas entre particular/universal, também apontadas no texto de Gomes, que levaram a América Latina a enfrentar o incômodo lugar conferido pela ideia de "cor local". A partir desta tensão histórica, o artigo desloca-se pelas reapropriações do termo cosmopolitismo que atualmente têm mobilizado as discussões nas Ciências Sociais. Nesta perspectiva, Figueiredo 
analisa as novas dinâmicas dos trânsitos efetuados pelas populações mundiais em uma tentativa de reacomodação dos territórios mobilizada pelos desafios impostos pelas atuais políticas do capital. Para isso, convoca três filmes que evidenciam as problemáticas fronteiras que se constituem nestes novos processos cosmopolitas: Cachê (França/Áustria/Alemanha/Itália, 2005), de Michael Haneke; Terra Estrangeira, de Walter Salles e Daniela Thomas (Brasil/ Portugal, 1995) e Entre os muros da escola, de Laurent Cantet (França, 2008).

O artigo de Tatiana Oliveira Siciliano - "O Theatro Municipal de Arthur Azevedo: as Várias Narrativas sobre o Teatro na Mídia Impressa" - também vai ao encontro das discussões propostas por Renato Cordeiro Gomes ao abordar a virada do século XIX para o século XX como um importante momento em torno das diferentes articulações acerca dos nossos projetos de modernidade em diálogo com um espírito cosmopolita que se consolidava no espaço urbano do Rio de Janeiro. Também é na complexidade das discussões sobre um projeto cosmopolita presente na nossa modernidade que a autora apresenta uma discussão acerca das disputas envolvidas na campanha pela construção do Theatro Municipal no Rio de Janeiro desde o final do século XIX, enfocando, sobretudo, a participação do dramaturgo Arthur Azevedo neste cenário. O que está em questão, ao longo do seu artigo, é a própria construção do campo intelectual na sociedade carioca (e brasileira) em articulação com o crescimento da mídia impressa e os discursos que se projetam em torno da legitimidade do teatro não apenas como importante manifestação de um processo civilizatório (Arte clássica), mas também como indício de um crescimento da indústria do entretenimento. Assim, nosso espírito moderno reivindicava um cosmopolitismo no qual as mídias atuavam de forma preponderante, inclusive como um campo onde se definia o papel do intelectual na Primeira República articulado ao desenvolvimento dos meios de comunicação de massa, criando "o lugar de fala" destes agentes a partir de uma legitimidade junto às camadas populares. Percebemos que o que está em jogo no texto são as disputas em torno dos projetos de cidades que insistem em afirmar um desejo cosmopolita que, no final das contas, ainda se encontra em processo na contemporaneidade, como percebemos no artigo de Fabio Raddi Uchôa: "Espaços e Imagens da Gentrificação no Centro de São Paulo".

No seu artigo, Uchôa analisa, a partir dos preparativos para Copa do Mundo 2014 (FIFA), o processo de gentrificação do centro da cidade de São Paulo e os conflitos sociais decorrentes desta intervenção. Esta "requalificação do espaço urbano", efetuada de maneira arbitrária por uma parceria neoliberal entre o poder público e a iniciativa privada, redesenha o espaço urbano fomentando discursos higienizantes, atuação de modelos de vigilância policial e deslocamento de populações. Essa gentrificação do espaço da cidade atende a determinados padrões globalizados já experimentados por outras cidades sedes de eventos 
internacionais do porte da Copa do Mundo, o que insere o Brasil, e São Paulo, especificamente, nessa nova experiência cosmopolita. Uchôa está interessado em investigar como esse processo se afirma na produção audiovisual contemporânea a partir de dois grupos de imagem: a publicidade televisiva realizada pelo Grupo INK e a minissérie Amor em 4 atos, produzida pela Rede Globo e dirigida por Tande Bressane, Tadeu Jungle e Bruno Barreto.

Enquanto as discussões em torno da representação da cidade gentrificada nas narrativas audiovisuais televisivas constituem o eixo do trabalho de Fabio Uchôa, Felipe de Castro Muanis propõe uma discussão pautada nos processos de constituição de uma linguagem na televisão brasileira, a partir dos imperativos do fluxo que as experiências da MTV Brasil introduziram no repertório nacional. No seu artigo - "MTV Brasil e o Ocaso do Fluxo" -, Muanis discute como essa modernização na forma de se fazer televisão, em diálogo com as experiências da matriz norte-americana, tensiona a cultura audiovisual brasileira e o mercado fonográfico do país. Aqui, a observação da presença da MTV Brasil vem acompanhada de uma reflexão teórica sobre o fluxo televisivo e o impacto que esta nova experiência espectatorial teve na tradicional grade de programação, promovendo uma discussão entre a tradição e a modernidade no interior da história da televisão brasileira.

Também pensando em dinâmicas de espectatorialidade, Felipe da Silva Polydoro se debruça - no artigo intitulado "Sob o Risco do Natural: Acidente e Repetição em Flagrantes de Desastres da Natureza" - sobre as coleções de testemunhos audiovisuais anônimos em torno dos desastres de características naturais em todo o planeta. A onipresença de câmeras parece globalizar a experiência, atestando o arrefecimento do elemento surpresa e inserindo o acaso como organizador de tais registros. Estes flagrantes de eventos, segundo o autor, dialogam com registros de outras naturezas, configurando um amplo contexto midiático contemporâneo, no qual se percebem as fricções em torno da ideia de uma suposta objetividade documental do fato e uma subjetividade que acompanha um olhar sensorial.

As problematizações entre o centro e a periferia voltam com força no artigo "O Discurso Periférico no Centro da Narrativa Midiática", de Guaciara Barbosa de Freitas, que, a partir da análise do programa Central da periferia, apresentado por Regina Casé, encaminha uma reflexão, conduzindo sua argumentação através da discussão sobre os protagonismos em jogo nos modelos de representação das periferias. A autora identifica os agentes sociais que se apresentam e os processos culturais que convertem o universo das mídias em um campo permanente de disputa em torno dos lugares de fala e dos embates em torno dos projetos de hegemonia e contra-hegemonia. 
Por sua vez, Marcio Serelle propõe uma reflexão sobre "A Dialética do Localismo e do Cosmopolitismo nas Narrativas Gráficas de Marjane Satrapi". Quadrinista e cineasta iraniana radicada na França, com suas HQs e filmes Satrapi constroi uma imagem das mulheres do Irã, desconstruindo estereótipos com que comumente as iranianas são representadas no Ocidente. Para isso, como demonstra o artigo de Serelle, ela aciona elementos de um local definido - o Irã -, mas desde a condição do exílio e ao mesmo tempo com uma linguagem que tende para o pop, que surge de maneira imprevista como um dispositivo discursivo no lidar com experiências traumáticas, situações de limite, como as que são decorrentes da violência contra as mulheres no contexto iraniano.

Situações de limite também estão em pauta no artigo "Revendo Imagens do Povo pela Locomoção e Politização", de Samuel Paiva e Joyce Cury, com foco relacionado ao Brasil, considerando filmes documentários que, voltados às propostas do Movimento Passe Livre, foram produzidos acerca das manifestações ocorridas em várias cidades brasileiras em junho de 2013. A noção de locomoção aqui está associada a uma politização que leva em conta as tensões e deslocamentos entre regiões diversas do Brasil, considerando-se aspectos históricos refletidos, no campo do cinema documentário, em experiências como a da Caravana Farkas, dos anos 1960, que os autores do texto comparam com produções cinematográficas contemporâneas, mostrando como a ideia de reforma agrária, tão recorrente antes, dá lugar à perspectiva da reforma urbana, premente nos dias atuais.

Por sua vez, o artigo "Retrato Invulgar do Cotidiano e Subversão de Gêneros no Cinema de Anna Muylaert", de Claudio Coração e Rosana de Lima Soares, confirma o caráter de interlocução que caracteriza a experiência dos autores incluídos neste dossiê. De fato, o texto dialoga intensamente com as proposições já referidas de Renato Cordeiro Gomes acerca das noções de "cosmopolitismos", confrontadas a outros conceitos, como "globalização", "multiculturalismo" e mesmo "cinema impuro". Coração e Soares aplicam tais concepções ao campo do audiovisual, mais precisamente ao universo dos gêneros cinematográficos, discutindo tensões que marcam a circulação dos discursos cinematográficos por locais diversos. Voltamse especialmente ao cinema de Ana Muylaert, observando atentamente os filmes Durval discos (2002) e É proibido fumar (2009), tomados como experiências de uma urbanidade simultaneamente cotidiana e excepcional.

Assim, estão apresentados todos os artigos que compõem este dossiê, em uma perspectiva que, como afirmamos desde o início, muito revela do GT Cultura das Mídias. Mas cabe destacarmos com ênfase que, ao produzir as reflexões que ora se colocam a partir de um mesmo eixo temático, e com visões diversas em diálogo, nosso intento de fato, enquanto grupo, é interagir não só internamente, mas ampliar as interlocuções com outros interessados em compreender fenômenos midiáticos 
como motores da cultura. Eis mais uma razão para os "cosmopolitismos" como uma ideia no plural, com intentos de conhecimento que, na verdade, também são muitos, ainda que o método preveja as mídias como pontos de partida, como suas formas complexas de circulação, pelo que, consequentemente, temos muito ainda o que pesquisar. Mas o trabalho vem sendo feito, como comprova esta publicação que os leitores ora têm diante de si e com a qual estão convidados a também dialogar. Pois então, sejam bem vindos e boa leitura!

Samuel Paiva

Maurício de Bragança 